\title{
AS NOVAS TENDÊNCIAS DO DIREITO INTERNACIONAL PRIVADO*
}

$\overline{\text { (Diego P. Fernández Arroyo) }}$

Introdução; I.A Internacionalização do Direito Internacional Privado; II.A Cultura Pós-moderna; III. Direitos Humanos; IV. Privatizaçăo do Direito; Conclusōes - relações Brasil e Argentina

\section{Introdução}

O Direito Internacional Privado (DIPr) apresenta quatro grandes tendências na atualidade. A primeira delas está na sua internacionalização. Embora num primeiro momento possa parecer tautologia, é notável que o DIPr torna-se cada vez mais internacional. Há pouco tempo, em realidade, havia muitos Direitos Internacionais Privados, como o DiPr brasileiro, com fontes exclusivamente nacionais. E, no Brasil, em particular, havia uma área menor de estudo, de pesquisa jurídica. O DIPr apresentava-se como matéria não obrigatória nas Universidades. Vê-se uma diferença significativa dessa realidade nos últimos 5 ou 10 anos. Há cursos de especialização em Direito Internacional em geral, de DIPr em particular. Em todas as Universidades brasileiras importantes, vê-se publicações que já não entram em nenhuma biblioteca, com uma quantidade enorme de livros, com crescente importância dada às fontes internacionais.

A segunda tendência está na influência da cultura pós-moderna e futurista no DIPr, Embora mais filosófica que a tendência anterior, apresenta igualmente grande importância na realidade dos sistemas jurídicos da atualidade.

A terceira tendência encontra-se na influência dos Direitos Humanos, que sempre se apresentaram como elementos de Direito Público, muito ligados ao Direito Constitucional e, portanto, mais relacionados ao Direito Internacional Público. Contudo, nos últimos anos, os Direitos Hưmanos têm influenciado enormemente o DIPr.

Finalmente, a quarta tendência, que talvez também possa se constituir uma tautologia, é a privatização do DIPr, que cada vez mais, apresenta-se nas mãos dos atores privados da sociedade. A seguir, analisarei essas quatro

Palestra apresentada na Aula Magna de abertura da Quarta Fdiçāo do Curso de Especializaçăo "O Novo Direito Internaciona:", março de 2004, Faculdade de Direito/UFRGS. O autor agradece a colaboração dos mestrandos Marilia Zanchet e Ricardo Medeiros de Castro. 
tendências, finalizando, nas conclusões, com seus reflexos nas relações entre os países do MERCOSUL, especialmente o Brasil e a Argentina.

\section{A Internacionalização do Direito Internacional Privado}

Há pouco tempo, no Brasil, havia poucas normas de DIPr. Havia a Lei de Introduçāo ao Código Civil, algumas regras processuais e, sobretudo, o Regulamento do Supremo Tribunal Federal. Nos últimos 10 anos, o Brasil incorporou ao seu ordenamento jurídico, uma quantidade importante - principalmente pela qualidade das leis - de Convençōes de DIPr. Em que pese as regras internacionais não sejam um tema solucionado e pacífico na jurisprudência, nem na doutrina brasileira, os juizes - em particular os membros do Superior Tribunal de Justiça e do Supremo Tribunal Federal - têm se deparado com um número crescente de causas envolvendo situações internacionais. Diante disso, precisam aplicar não essas poucas regras do ordenamento nacional brasileiro, mas regras que estāo em vigor no Brasil, que podem ser regras que tenham origem na Organização dos Estado Americanos, no Mercosul, na Conferência de Haia, na UNCITRAL, ou ainda no UNIDROIT.

Embora não se saiba exatamente qual a posição dessas regras no ordenamento jurídico do Brasil, todas estão vigendo. Na Argentina, o componente internacional já é há tempos mais importante que o nacional no sistema do DIPr. Uma prova disso está na Reforma Constitucional de 1994, em que a Argentina colocou o Direito Internacional claramente numa regra positiva, com hierarquia superior às regras do Direito Nacional. Neste país, a jurisprudência da Corte Suprema é unânime, no sentido de que o Direito Internacional de fonte internacional, ou seja, o Direito Internacional verdadeiramente internacional, tenha aplicação prioritária às regras de cunho eminentemente nacional.

Altera-se, portanto a perspectiva, já que tais normas são aceitas pelos Estados, mas não são por eles elaboradas. Por exemplo, a UNCITRAL é um órgão pertencente às Nações Unidas, no qual participam cerca de 60 países, de forma alternada. Desses 60 Estados, há vários latino-americanos. No momento, estão presentes o Brasil, a Colômbia, o Paraguai, o Uruguai e o México. Em reunião ocorrida em Nova lorque, no mês de março, discutiu-se uma questão muito importante para os países em desenvolvimento, exatamente por serem países que necessitam de crédito: a elaboração de é uma guia legislativa sobre garantias, isto é, bens que podem ser oferecidos em garantia por dívidas. De todos os países mencionados, que no momento fazem parte da UNCITRAL, apenas a Colômbia enviou representante na discussão. Nenhum dos outros mandou qualquer representação. A Argentina, que estava na condição de observadora, enviou 2 representantes, porém que nada podiam fazer.

Ocorre que tais regras são aprovadas nos organismos internacionais e depois se transformam em regras positivas nos Estados, sem que eles tenham participado da sua elaboração. Então, é difícil que essas regras contemplem os 
interesses dos diferentes Estados, sem que haja representantes defendendo a respectiva posição. No âmbito internacional, estão-se elaborando regras praticamente sobre todos os assuntos. De fato, tem sido muito mais importante o que se está mais elaborando em nivel internacional do que nacional, como na Conferência de Haia, da UNCITRAL, na UNIDROIT. Alguns países, como a Venezuela, elaboraram uma boa lei de DIPr. Contudo, constitui exceção. Portanto, deve haver consciência por parte dos países latino-americanos da importância na elaboração das regras no âmbito internacional, já tais regras farão parte do ordenamento jurídico nos diferentes sistemas jurídicos. Além disso, mesmo que esses países não ratifiquem as Convenções, elas se transformam em modelos, que expressam uma tendência e acabam sendo copiadas pelos legisladores dos Estados, acabando, enfim, a fazer parte dos ordenamentos nacionais. Muitos Estados, dentre eles os latino-americanos, necessitam de boas estruturas nacionais, mas não valorizam as convençōes que já foram internalizadas.

Refere-se, também, o Direito Transnacional, que não depende nem de países, nem de organismos internacionais. Situa-se num território quase virtual, criado pela prática internacional, sobretudo pelo comércio internacional, que muitas vezes possui fontes reconhecidas, como a Câmara de Comércio Internacional de Paris; outras vezes, entretanto, não possui nenhuma. Existe na forma de regras que se aplicam no caso de transações comerciais internacionais às quais os comerciantes e empresários necessitam observar. Porém tais regras não se encontram nos Códigos, como o Brasileiro, ou o Venezuelano. Ainda há países que não apresentam posição definitiva quanto à aplicação da autonomia da vontade no comércio internacional, como o Brasil, e outros que realmente próbam, como no caso do Uruguai. Dessa forma, näo se permite a escolha do juiz e da lei aplicável, ou o recurso à arbitragem internacional. No Uruguai, quando os exportadores querem comerciar seus produtos com a Europa, têm de assinar contratos que reconheçam a jurisdição inglesa e a lei aplicável de Nova lorque, por exemplo. Há duas possibilidades: ou vender os produtos e adotar tais imposiçōes, ou não vender. $E$, é claro, geralmente preferem vender. Há, portanto, discursos divorciados: o discurso dos realistas e o discurso daqueles que acreditam, ou que fazem seus alunos acreditarem, estar defendendo a soberania do país e algumas regras que, em realidade, não trazem qualquer proveito para os empresários, ou exportadores. Esse chamado Direito Transnacional é, dessa forma, realidade.

Outro exemplo encontra-se na arbitragem. Tradicionalmente, na América Latina, a arbitragem era vista como algo suspeito, sobretudo pelo Judiciário, que a considerava um competidor desleal. Imaginava-se que a arbitragem não apresentava estrutura segura, mas que, mesmo assim decidia casos de milhões de dólares. Isso está mudando agora. Hoje, a arbitragem passa a ser reconhecida em todos os países do mundo, mesmo naqueles em que não há uma rendição ao 
capitalismo, a exemplo de Cuba. Todos os contratos internacionais assinados por empresas cubanas apresentam cláusula de arbitragem. Além disso, todas as sentenças arbitrais dos tribunais de Nova lorque e Paris, entre outros, são executadas sem nenhum problema em Cuba. Certamente, não há país que mais argumente politicamente a respeito da soberania do que Cuba. Na prática, contudo, as decisões de comércio internacional não são tomadas em muitos casos pelas autoridades judiciárias do país, porém são feitas por advogados e professores que trabalham em órgãos arbitrais.

$O$ último elemento desta primeira tendência encontra-se na influência do princípio da eficiência no DIPr. O princípio da eficiência é muito lógico, desde uma perspectiva econômica: as normas jurídicas devem ser feitas para facilitar o funcionamento do mercado e não para obstaculiza-lo. Contudo a noção de eficiência enquanto valor jurídico supremo apresenta-se não só perigosa como igualmente rara em inúmeras matérias. Ele pode ter boa aplicação em áreas patrimoniais, tais como contratos e responsabilidade civil, áreas que habitualmente são tratadas pela Análise Econômica do Direito. Embora alguns autores norte-americanos sustentam ser o princípio da eficiência basilar no DIPr, muitas são suas limitações. Temas como adoção de menores, ou direito internacional de família em geral, direito do consumidor e direitos dos trabalhadores não sāo passíveis de ser submetidos - ao menos não exclusivamente - a noções economicistas.

\section{A Cultura Pós-moderna}

A primeira influência da cultura pós-moderna, ou, como alguns afirmam, pós-pós-moderna, está na flexibilidade. Em geral, a pósmodernidade jurídica significa a ausência do absoluto. Assim, a idéia de Código, de tratados internacionais que abranjam todas as situaçōes possiveis já nảo se persegue. Hoje se trabalham temas concretos, aquilo que se mostra importante em certo momento.Vai-se, então, construindo um colar de regras internacionais, dependendo das necessidades, o que é extremamente positivo. Entretanto pode ocorrer de países adotarem essas regras sem refletirem nas conseqüencias, com a possibilidade de que sejam incompatíveis, inclusive, com a própria Constituição. A Convenção Internacional apresenta-se um modelo de unificação rígido. Os Estados podem ou não ratificar. E, quando o fazem, podem estabelecer alguma reserva, em virtude da necessidade de adaptá-la à Ordem Pública do país. Na atualidade, as organizações internacionais apresentam formas muito distintas de legislar: algumas vezes realizam convençōes, outras utilizam métodos de soft law e elaboram leis-modelo, ou guias legislativas. Recentemente, a UNCITRAL elaborou uma guia legislativa sobre insolvência e está finalizando outra sobre garantias mobiliárias. 
Essas guias assemelham-se a livros pedagógicos, com recomendações para serem levadas em conta ao reformar a ordem interna sobre determinado tema. Não raras vezes, tais produtos legislativos dos organismos internacionais apresentam metodologia mista. A Convenção das Nações Unidas, por exemplo, de 2001, sobre cessão de créditos, apresenta uma parte na forma de convenção, na qual o último capítulo é optativo. Assim, o país deve ratificar a Convenção, mas não necessariamente o Capitulo $V$, que rege regras sobre conflitos de leis. Apresenta, também, um anexo, que constitui uma lei-modelo. Portanto, é um produto hibrido que se oferece aos Estados para que adotem o modelo que melhor se adeqüe ao seu ordenamento. Embora esses produtos legislativos sejam de grande qualidade técnica, ao mesmo tempo, podem oferecer muita dificuldade aos legisladores nacionais, pois exigem conhecimentos específicos.

O segundo dado da influência pós-moderna é, também, a pluralidade. Nenhuma técnica é absoluta. Pode-se mesclar várias técnicas legislativas e várias matérias jurídicas na mesma convenção, como a Convenção sobre Proteção de Menores da Conferência de Haia, já que há regras sobre jurisdição, direito aplicável, cooperação, reconhecimento de sentenças, constituindo atitude absolutamente nova no contexto da legislação internacional.

Por fim, o terceiro elemento da influência pós-moderna é o chamado Diálogo das Fontes, de que tem tratado Erik jayme e, aqui no Brasil, Cláudia Lima Marques. Tem-se apresentado muito difícil não só para os legisladores dos Estados, mas sobretudo aos juízes saber como devem aplicar as regras. Mesmo em países onde claramente está estabelecida hierarquia entre regras internacionais e nacionais, o aplicador da lei deve mover-se: ir e voltar entre regras nacionais e internacionais. Embora a hierarquia constitua um princípio para compreender o sistema, nos casos práticos, quando se devem aplicar convençōes, o juiz se vê obrigado a aplicar também regras nacionais. Essa circunstância exige cada vez mais especializaçāo por parte dos aplicadores do direito. Os problemas envolvendo o Direito Internacional apresentam-se em fase de transformação, em função da maior integração entre os paises, o crescente número de viagens e negócios internacionais. Além disso, há um crescente número de estrangeiros nos países, que compram, casam, têm filhos, etc. Tais problemas podem trazer menor ou maior importância econômica, mas muitas carecem, ainda, de respostas nos ordenamentos nacionais. Em suma, em virtude da pluralidade de fontes, torna-se cada vez mais dificíl solucionar os casos internacionais que se apresentam sem uma adequada especialização. 


\section{Direitos Humanos}

Costumava-se mencionar os Direitos Humanos no Direito Internacional com relação ao DIPr Substantivo. Quando se referia os Direitos Humanos, era para relaciona-los à Ordem Pública. Por exemplo, não se reconhece a poligamia, que é válida nos países muçulmanos, pois essa é atentatória ao princípio da monogamia e ao princípio da isonomia entre homens e mutheres. Essa realidade constitui tema de milhares de casos em países europeus, em virtude da imigração de pessoas oriundas de paises onde o direito apresenta raiz religiosa no Alcorão. Porém, na atualidade, um tema de destaque na jurisprudência européia encontra-se na influência dos Direitos Humanos nos aspectos processuais do DIPr, sobretudo no que pertine ao princípio do acesso à justiça. Essa regra existe em todas as Convenções de Direitos Humanos, na Convenção Européia, na Convenção Universal, na Convenção Interamericana, no Projeto de Constituição Européia, apresentando crescente importância em muitos casos de aplicação do DIPr. Tanto a Corte Européia, como as Cortes Constitucionais de diferentes países europeus têm tido a necessidade de se pronunciar sobre o problema.

Há três anos, na Espanha, uma mulher armênia, que morava no País Basco, no Norte da Espanha, queria divorciar-se de seu marido, também armênio. A lei espanhola considerava aplicável ao divórcio a lei da nacionalidade comum dos cônjuges. Aplicava-se, então, a lei da Armênía. Ocorre que a mulher queria divorciar-se o quanto antes e ofereceu provas do Direito Armênio, que se encontrava em fase de transição, já que o país foi parte da ex-União Soviética. Dessa forma, não havia uma lei armênia propriamente dita, apenas o Código Civil da ex-União Soviética, constituindo um grande problema comprovar essa realidade ao juiz de Bilbao, na Espanha. De qualquer forma, a mulher apresentou cópia do Código da ex-União Soviética com o carimbo do Consulado. Ao decidir, porém, o juiz afirmou não estar convencido da prova do Direito Armênio apresentado pela mulher e decidiu negar o divórcio. Deixou, portanto, de analisar o mérito, não aplicando a lei espanhola, refutando a demanda. Em grau de apelação, confirmou-se a sentença. A mulher insistiu, indo ao Tribunal Constitucional Espanhol, através de uma Ação de Amparo, alegando violação a direitos fundamentais. Ao decidir, a Corte Constiłucional Espanhola entendeu que negar o divórcio por problema de prova do direito estrangeiro constitui violação a direito fundamental, que se encontra acima do requisito de prova. Enfim, para defender esse direito fundamental - o direito fundamental ao divórcio - o juiz deve declará-lo, independentemente, da aplicação da lei da Armênia, da Espanha, ou do Congo. Isso demonstra que tais questões passam a ser vistas a partir da defesa dos direitos fundamentais.

Todos os tribunais de países europeus, incluindo o próprio Tribunal de Justiça Europeu, devem reconhecer o art. 6 da Convenção Européia dos Direitos 
Humanos, que garante o acesso à justiça. Dessa forma, sentenças que tangenciem assuntos como competência, jurisdição, direito aplicável, reconhecimento de sentença devem ser analisadas a partir da perspectiva da hipótese de violação a direito fundamental. Certamente, essa constitui análise muito mais importante do que a comumente utilizada em relação aos Direitos Humanos no DIPr como direito substantivo. Essa feiçāo processual dos Direitos Humanos tem tido um desenvolvimento muito maior e mais interessante, pois ele também está levando à análise do respeito às diferenças. Sem dúvida, um novo campo para o desenvolvimento desse direito na Europa e nos Estados Unidos são as uniões de pessoas do mesmo sexo. Há poucos anos, era difícil discutir ou pensar o tema do divórcio. Poucos anos depois, já se discute os efeitos das uniōes de pessoas do mesmo sexo, já havendo lei ejurisprudência que as amparam. Na atualidade, num mundo onde é muito fácil mudar de país, conhecer pessoas de outras culturas e países, esse passa a ser tema central do DIPr pessoal.

Nos Estados Unidos, há outro problema muito importante, que também deve ser analisado a partir dos Direitos Humanos. Ocorre que o juiz competente para julgar determinado caso decide não conhece-lo, porque envolve outra jurisdição mais apropriada. É a instituição denominada de forum non conviniens. Embora pareça muito lógica essa noção do juiz mais conectado ao caso, mesmo funcionando muito bem nos Estados Unidos para os casos interestaduais, nem sempre é a melhor solução. Uma companhia petroleira, durante muitos anos, poluiu um grande lago no Equador. Em conseqüência, muitos habitantes de uma aldeia indigena atingida morreram de câncer, muitos outros estão doentes. Alguns advogados convenceram as pessoas dessa aldeia a entrar com uma ação nos Estados Unidos contra a companhia petroleira. Segundo a jurisprudência da Corte Suprema Norte-Americana, o juiz competente é o do domicilio da sede da empresa. Contudo, os advogados da empresa petroleira tentaram convencer o juiz americano que, neste caso, o melhor juiz seria o equatoriano, pois conhece melhor a situação do caso e das partes envolvidas e está mais perto para pegar as provas, isto é, apresenta-se como o juiz mais conveniente. Infelizmente, o grande problema é que o Judiciário da maioria dos Estados da América Latina não conta com os meios, nem as condiçóes para solucionar casos dessa envergadura. Além disso, o valor da vida cotidiana nos países latino-americanos é, em geral, muito menor do que nos Estados Unidos, o que se reflete nas indenizações dos Tribunais. Refere-se, ainda, que a justiça norte-americana busca penalizar aqueles que provocam grandes danos sociais, assim como, que as demandas se iniciam e atingem seu fim em um periodo razoável. Na América-Latina, em muitos casos, os processos podem se prolongar para além da vida das vítimas. Na maioria das vezes, o sucesso do forum non conviniens deve-se ao fato de que os advogados norte-americanos estão mais familiarizados ao sistema do seu país do que os advogados dos reclamantes. Constata-se, então, que essas pessoas 
encontram-se em muita dificuldade para obter uma indenização razoável. Portanto, os países latinomamericanos deveriam pensar em propor soluçōes não só para os casos nacionais, mas também em nível internacional, por exemplo, através de uma regulamentação interamericana feita na OEA.

\section{Privatização do Direito}

Cada vez mais está presente a noção da autonomia da vontade como princípio do DIPr: não apenas uma tendência, uma possibilidade ou uma opção, mas um verdadeiro princípio. Constata-se isso nas Convenções Internacionais e nas regras nacionais dos últimos anos, tanto no âmbito comercial, como no âmbito familiar, constituindo uma mudança profunda, cujo significado nem todos estão bem conscientes. Assim, as partes podem, em muitas relações jurídicas, escolher, com certas limitações, o direito aplicável e o juiz ou árbitro competente, bem como o conteúdo material dessas relações jurídicas. Nos últimos anos, se vê que essa autonomia tem significado, também, autonomia para elaborar regras de alcance geral. A UNIDROIT, por exemplo, elaborou convenção relativa a garantias sobre bens móveis de grande valor, tais como aeronaves, materiais ferroviários e objetos espaciais. Nesta organização, assim como nas demais, são os representantes dos países que elaboram as soluções. Quando se vai ao fórum, contudo, e se busca a origem de tais soluções, se encontra, por exemplo, um memorando preparado pelas grandes companhias fabricantes de aeronaves, em que se defendem os princípios e as soluções que uma regulamentação de garantias nesse setor deve conter. Tais princípios e soluções estão, em sua maioria, presentes na Convenção aprovada na Cidade do Cabo, em dezembro de 2001. Da mesma forma, quando se analisa a LeiModelo Interamericana sobre Garantias Mobiliárias, se pode questionar por que os representantes dos países americanos consideram importante regulamentar tal tema, sem dúvida, um tema que precisa de modemização na América Latina. Verifica-se, na realidade, que os grandes bancos norteamericanos eram os mais interessados nessa lei. Assim, financiariam um centro acadêmico em Tucson, Arizona, Estados Unidos, chamado Centro Nacional de Direito para o Livre Comércio Interamericano. Nesse Instituto, se fez um anteprojeto, o qual, após determinadas modificações, originou a Lei-Modelo interamericana aprovada em 2002. Ademais, o diretor desse instituto foi o delegado norte-americano nas discussōes da OEA. Sem dúvida, a inter-relação entre interesses públicos e privados é sinal dos tempos. Entretanto, ocorre que os Organismos Interamericanos, sobretudo a OEA, apresentam, na realidade, um processo de terceirização. Os instiłutos privados recebem financiamentos de grandes companhias e fazem os projetos, que säo posteriormente aceitos pelos representantes dos Estados. Infelizmente, muitos estados não podem sequer enviar um representante, por falta de verba, ou, ainda, por inexistir quem conheça da matéria. 


\section{Conclusões - relações Brasil e Argentina}

Diante dessas tendências apresentadas, deve-se reforçar, por fim, as boas relações entre países latino-americanos, como o Brasil e a Argentina, o que traria grande impacto positivo para o DIPr desses países. Seria muito bom e nada difícil que ambos os países adotassem posições comuns não só em relação a temas já elaborados, através de leis-modelo, convenções, etc, mas também para os futuros trabalhos nos organismos internacionais. Se já se está fazendo isso, por exemplo, no Conselho de Segurança da ONU, muito mais fácil seria fazê-lo em organismos técnicos, como a UNCITRAL ou o UNIDROIT. No momento, o Brasil é membro do Conselho de Segurança e a Argentina, não; sempre, há, porém um diplomata argentino na representação brasileira. Também se está verificando um plano piloto de colaboração consular, através do qual há funcionários argentinos no Consulado Brasileiro, em Boston, e funcionários brasileiros no Consulado Argentino, em Hamburgo. Portanto, os países poderiam apresentar temas comuns para que ganhem força. Além disso, deve-se cogitar a representação unificada. De fato, é bastante difícil enviar representantes para todas as reuniöes da UNCITRAL, principalmente especialistas. Então, se tornaria menos dispendioso, se o Brasil e a Argentina, ou todos os países do Mercosul, tivessem ao menos um representante que conhecesse a matéria. Verifica-se que os países acabam enviando como representante alguém que esteja trabalhando em embaixada próxima, que, porém, muitas vezes não conhece o tema. Dessa forma, torna-se muito pouco o que se pode sugerir e limitadas as discussões de que se pode participar.

Há, ainda, outro tema relevante. Os ministérios, em especial, os de Relações Exteriores e de Justiça, necessitam possuir relação com especialistas, para que possam elaborar idéias, regras e propostas para apresentar no âmbito internacional. Se é possível que multinacionais apresentem propostas de Convenções, então por que institutos universitários também não podem fazelo, aproveitando dessa privatização um tanto paradoxal?

Enfim, deve-se apresentar uma política de temas a ser debatidos nestes fóruns internacionais, que interessem aos nossos países, nossas sociedades, nossas empresas, nossos consumidores, sempre buscando a possibilidade de trabalhar os Direitos Humanos como base de todas as regras. Não o respeito aos Direitos Humanos enquanto idéia vaga, geral, de discursos políticos, mas no sentido dos Direitos Humanos de terceira e quarta gerações, de proteção dos consumidores, das partes mais fracas, aproveitando a privatização, que nos âmbitos universitários pode dispor da comunicação. Mesmo aqueles que não gostam de Direito Internacional podem se comunicar para estabelecer interesses, problemas das suas diversas comunidades. Como diz o profeta lim Morrinson, o futuro deve ser melhor que o presente, e todos temos responsabilidade para que isso ocorra. 